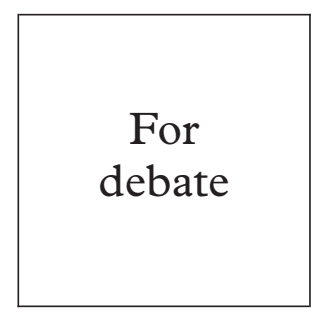

\section{Ethics committee review of medical audit: a personal view from the United Kingdom}

\author{
Martin Talbot
}

Central Sheffield University Hospitals, Royal Hallamshire Hospital, Sheffield S10 2JF, UK M Talbot

Correspondence to: martin.talbot@csuh.nhs.uk

Accepted for publication 19 September 2000
Until now, medical practice in the United Kingdom has, unlike in medical research, largely resisted ethics committee scrutiny of clinical audit. I support this position. On what grounds do I do so? Are there sufficient differences between medical research and medical audit to reliably sustain this thesis? I shall argue that research ethics committees may be operating under philosophical constraints which, in the main, go unrecognised; they therefore have no, as it were, prima facie rights and their potential involvement in medical audit raises serious questions, not least because audit is a creature of an entirely different nature from research. For me, the situation is straightforward but others, of course, are welcome to refute my assertions.

It is said that research is finding out how one should be doing something, and audit whether one is actually doing it, or, as Rawlins says, "Research discovers the right thing to do: audit ensures that it is done right." ${ }^{1} \mathrm{He}$ explains the view of the British Medical Association's clinical audit committee and calls for a scrutiny of proposed audit projects by audit ethics committees, rather than ethics research committees. But he rather begs the question of the validity of this position by suggesting that, otherwise, ethics research committees would be overburdened by work. Taking the contrary view, the Royal College of Physicians clearly states that medical audit (among other activities such as epidemiological surveillance and morbidity and mortality reviews) is medical practice and, as such, does not require ethical review. ${ }^{2}$ Kinn disagrees with most definitions of medical audit, believing that the purpose of audit is to "raise general clinical standards" (and thus, I interpret her to say, has more in common with research) yet refers only to specific instances where audit must be based on sound ethical principles. ${ }^{3}$

I suggest that the two operations of research and audit are different, although others differ. Although a recent survey of health authorities' views has acknowledged similarities that include a systematic, rigorous approach to data collection and a number of common methodologies. ${ }^{4}$ Also, it is by no means clear, for example, that audit is carried out in the clinical sphere and research is not, since all of us can think of many examples of first rate clinical research. And so, Rix and Cutting suggest that not to open up audit to outside review is paternalistic. ${ }^{5}$ They see very few, if any, differences between the two activities, and deny that research is always productive of new knowledge. Audit, on the other hand, may generate new understandings: these may, in turn, be introduced into daily clinical practice and, therefore, require scrupulous external review. Smith agrees ${ }^{6}$ and $\mathrm{Kinn}^{3}$ makes the case for ethical review before the submission for peer reviewed publication of a sufficiently meritorious audit project. However, I rather subscribe to the view of Häyry, who has said that paternalism is:

“ . . demolished at a stroke by asking the subject what they would have chosen if their will ... (were) ... not encumbered ... (or if they) ... wish us to find out if we are operating according to the available or acceptable standards of the day?"7 (p 32)

"Finding out if we are operating according to the available or acceptable standards of the day" is, I assert, audit. On the other hand, is all research the sort that requires external review, always capable of the kind of rigorous previous quantification which research ethics committees often seem to seek? Further, are the foundations of scientific medical research so fundamental that we can base a whole ethical system upon it? I believe the answers to these questions to be "No." The paradigm here is epistemology and the philosophy of science rather than moral philosophy, and devolves around questions such as, "What is knowledge?" (which may be unanswerable, and which Ayer considers to be relatively unimportant as a question" ${ }^{8}$ ), or rather "What propositions are true and how do we know them to be true?"

The most widely accepted definition of knowledge is "justifiable true belief." A seemingly fairly straightforward idea, yet from where have we acquired our ideas on the nature of knowledge, on how knowledge is acquired, and on how it is formed? The nature of knowledge is precarious: not only since knowledge itself seems continually to be changing, but because, as a concept, a definition of knowledge is notoriously elusive. From the dawn of early Western philosophy in ancient Greece, the Athenian scholars (particularly Socrates and Plato) are to blame for telling us that, firstly, there are absolute truths and, secondly, that the everyday, material world is an inferior copy of some perfect, transcendent one. ${ }^{9}$ The Athenians were particularly influential on the development of, firstly, Renaissance thought and, secondly, the thinking of the Enlightenment. This legacy was mediated by medieval scholars who were forced to utilise this "positivism" to champion the cause of the early church against the challenges of the heretics. 
Inseparable from this influence, there have been two major schools concerning how knowledge is acquired, each convinced of its correct interpretation-the empiricist school and the rationalist school. ${ }^{10}$ The empiricists (Locke, Berkely, Hume) claim that there is no true knowledge except that which is arrived at through our own perception; the rationalists claim (Descartes, Spinoza, Leibnitz) that knowledge is acquired by virtue of structured thinking and logic. Both claim to have stepwise affirmations as to how, a definition of knowledge notwithstanding, human beings grope towards "justified true belief." Each has been challenged and criticised by the sceptics, who claim that there is no sure way of knowing anything. Thus, the situation is not simple; as Bertrand Russell says:

“. . .we shall see a complicated structure where we thought everything was simple ... .we shall have become aware of the penumbra of uncertainty surrounding the situations which inspire no doubt ... .we shall find doubt more frequently justified than we supposed ...."11 (p 9)

So, every age from Socrates onwards has been convinced of its grasp on this truth, qua knowledge, and, until very recently, our own was no exception. As Robinson puts it:

"Most philosophers tend to be selective sceptics as a matter of course. They often declare that all previous philosophies are false, but that their own truths are castiron." (p 11) (my italics)

I am not suggesting that the sceptics are necessarily correct. At the least, to assert that there is no sure way of knowing anything is by way of saying that one is sure that one knows something-scepticism becomes a self defeating argument that falls at the first fence. However, my understanding of the sceptical position leads me to believe that it is reasonable to call into question the basic tenets of "scientific method." As Ayer puts it:

"... what the philosophical sceptic calls in question is not the way in which we apply our standards of proof, but these standards themselves."12 (p 36)

Yet we remain convinced, as clinicians and scientists, that the positivism we have inherited from the Enlightenment is the only way of elucidating truth. We forget (or choose to ignore) that the most we may hope to achieve is merely our truth and, as such, it is only a relative truth. We would do well to read and take notice of Karl Popper who has shown us quite clearly that the usual view that experiment leads to scientific hypothecation is wrong; it is rather that loose, or freely conjectured, hypotheses are tested against experience. Nothing can, therefore, be known with certainty although it is possible to approach truth more and more closely:

"Our theories are our inventions ... .may be merely ill-reasoned guesses, bold conjectures, hypotheses. Out of these, we create a world: not the real world, but our own nets in which we try to catch the real world."13 $(p$ 60)

Hypotheses that survive a testing process constitute the existing corpus of knowledge but, at the end of the day, such approximations are only conjectures and all available "evidence" has to be subjected to rigorous analysis with this in mind. Although this "falsificationism" is not without its critics, ${ }^{14}$ the situation is fluid: the objective becomes subjective and the subjective, objective. Robinson says:

"Most modern scientists grudgingly admit that the notion of 'objective scientific knowledge' is an illusion." " (p 52)

Research ethics committees (sometimes known as institution review committees in the United States) have grown up in response to a feeling that "something must be done" in order to protect the unwary public from the vicissitudes of unscrupulous scientists, and probably rightly so. Yet, in doing so, I believe that they only fortuitously represent the argument of those such as Popper, and only tacitly acknowledge the tensions of the philosophical position in their rather bureaucratic and reflex response to the issues before them. Sometimes, it seems, they flounder uneasily in a no-man's land between principle and casuistry and, on occasion, good sense is sacrificed upon the altar of rote. What place, therefore, may they have in the regulation of medical, or clinical, audit?

The argument is with the positivism of the Enlightenment, to which I have alluded earlier. The post-modern philosophers have produced convincing, although on occasion nihilistic, arguments against truths following naturally from the linguistic transcendence of, say, objective over subjective, science over artistry, or officially regulated over intuitive..$^{15}$ In the social sciences, anthropology and psychology, it is seen that significant truths (and, in turn, policy and practice) arise as much from qualitative research methodology as quantitative. ${ }^{16}$ Not only this but significant insights evolve from interpretation and analysis as much as from description. ${ }^{17}$ In some of this research (for example, interview studies, or educational research on classroom interaction) a technique of "grounded theory" may profitably be utilised in which an episode is visited and revisited, an open mind is kept throughout, and a coherent explanation for the observed phenomena gradually appears by repeated revision of one's hypotheses. These formulations, which I suggest have more in common with audit than quantitative, positivistic research, would sit uneasily with the kind of medical model which is usually dealt with by our research ethics committees. To paraphrase Wittgenstein, in the rough and tumble of ordinary life, we are more concerned with making sense than knowing. ${ }^{18}$ This begs the question of adapting ethics committees to cope with this kind of situation but I believe that there are other arguments for not going down that road.

In audit, more than in domain oriented research, we are in closer approximation to the doctor-patient interface. This is so even if we conduct retrospective, chart based audit. We measure care given at this interface against some arbitrary standard. If these standards are national, who is able to say that the fulcrum on which the project balances (the national standard) is a valid one? Almost certainly not a non-specialist, local committee. If, for the 
immediate purpose of audit, the clinicians themselves set the standards locally, is the local non-specialist committee more suited to refute these standards than the doctor who is in day to day contact with her patients? I think not. Further, the instigation and operation of ethics review committees suffer from many internal contradictions arising not only from the competing demands of moral philosophy but also from epistemological questions to which I have briefly alluded here. At the least, they suffer from the difficulty inherent in the question, "Assuming the science is right, what is the nature of the world?" They are merely (if merely be the right word) concerned with the twin questions, "Is the science right and is it equitably and correctly utilised?" In this, they embrace the philosophical position of instrumentalism in that they depend upon theoretical assumptions about the underlying structure of reality. ${ }^{19}$ Without realising it they suffer under a kind of blanket relativism. Clearly, the interests of the patient must be protected yet to claim that one may build a sturdy ethical edifice upon this foundation may, in itself, be shaky.

It seems very clear that the pursuit of knowledge, of all kinds and in all ways, is fraught with problems. However, in my clinical practice, whether I am an empiricist or a rationalist, a sceptic or a post-modernist, my knowledge or truth approaches more and more closely that knowledge or truth which matters - that of the patient. This gradual elision is expressed very closely by the critical reflection on my practice that is audit. Commonsense assumptions and taken for granted experiences are challenged through (usually) group reflection that unites critical thinking with experiential learning. ${ }^{20}{ }^{21}$ Although there are doubts about whether one can ever truly know the mind of another, ${ }^{11}$ there are those who would say that such congruence is achievable. ${ }^{22}$ To argue, as I do, that audit is to do with knowing others might be considered by some to be fanciful and stretching the issue more than necessary, yet I remain convinced that audit is closer in this "knowing one's patient" than is medical research. It is in the nature of an engagement with an "on the ground" problem and therefore runs closer and closer to "knowing others." Decades of careful observation of the practicum of experts were enough to convince the social scientist, Schön, that there is a rigour of compelling immediacy in this kind of critical reflection. ${ }^{23}$ Audit, by its very nature, is an exegesis of the practitioner's art. It does not need independent ethical scrutiny, and should not be subject to it.

1 Rawlins R. Local research ethics committees: research discovers the right thing to do; audit ensures that it is done ight. BMF 1997;315:1464

2 Royal College of Physicians. Independent ethical review of studies involving personal medical records. F Roy Coll Phys Lond 1994;28:439-43.

3 Kinn S. The relationship between clinical audit and ethics. $\mathcal{F}$ Med Ethics 1997;23:250-3.

4 Wilson A, Grimshaw G, Baker R, et al. Differentiating between audit and research: a postal survey of health authorities' views. BMF 1999;319:1235

5 Rix G, Cutting K. Clinical audit, the case for ethical scrutiny? Int f Health Care Quality Ass 1996;9:8-20.

6 Smith R. BMJ's preliminary response to the need for ethics committee approval. By email. (http://www.bmj.com/cgi/ committee approval. By email. (http

7 Häyry H. The limits of medical paternalism. London: Routledge, 1991.

8 Ayer AJ. The central questions of philosophy. Harmondsworth: Penguin Books, 1973.

9 Robinson D. Nietsche and postmodernism. Cambridge: Icon Books, 1999.

10 Hospers J. An introduction to philosophical analysis. 4th ed. London: Routledge, 1997.

11 Russell B. An enquiry into meaning and truth. Harmondsworth: Penguin Books, 1962.

12 Ayer AJ. The problem of knowledge. Harmondsworth: Penguin Books, 1956.

13 Popper K. Unended quest: an intellectual autobiography. London: Routledge, 1993.

14 Howson C, Urbach P. Scientific reasoning. La Salle: Open Court, 1989.

15 Powell J. Postmodernism for beginners. New York: Writers and Readers Publishing Inc, 1998.

16 Robson C. Real world research. Oxford: Blackwell, 1993.

17 Wolcott HF. Transforming qualitative data: description, analysis and interpretation. London: Sage, 1994.

8 Wittgenstein L. Tractacus logico-philosophicus. Trans Pears DF, McGuiness BF. London: Routledge, 1974.

19 Papineau D. Philosophy of science. In: Bunnin N TsuiJames EP, eds. The Blackwell companion to philosophy. Blackwell: Oxford, 1996.

20 Kolb DA. Experiential learning. New York: Prentice-Hall, 1984.

21 Dewey J. Experience and education. London: Collier MacMillan, 1938.

22 Buber M. I and thou. New York: Prentice Hall, 1984. 23 Schön DA. The reflective practitioner. Aldershot: Arena 


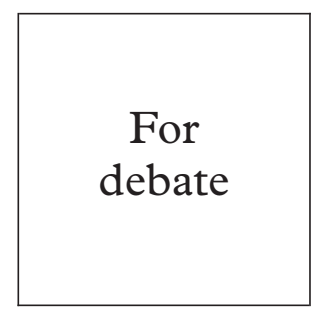

Selly Oak,

Birmingham B29 6RB

Thomas S Low-Beer

Correspondence to:

t.s.low-beer@bham.ac.uk

Accepted for publication 29 August 2000

\title{
Ethics committee review of medical audit: a personal view from the United Kingdom
}

\author{
Thomas S Low-Beer
}

If medical research proposals are subject to ethics committee scrutiny, should the same not apply to the process of clinical audit, which, it can be argued, is no more than another kind of potentially intrusive form of clinical investigation?

Dr Martin Talbot tries to tackle the question by first discussing how different clinical audit is from medical research, concluding that "research is finding out how one should be doing something"-clearly not an adequate definition of research, whereas "audit ensures that it is done correctly." He then continues with a philosophical digression on the nature of knowledge, in which he demonstrates his sympathy with a relativistic, postmodern view: one must beware of theoretical assumptions about the structure of reality, thereby encouraging one to keep an open mind on just about anything.

With this nihilistic attitude, he turns to a subjective approach, to his patients and his clinical practice, and concludes that because audit is closer to knowing one's patient than is medical research, there is no need for ethics committee scrutiny of audit proposals.

There are issues in this which, although not altogether subjective, are nevertheless matters of judgment: is the process of audit totally value free? If not, might anyone suffer as a result? Is this a problem which might be sufficiently widespread and serious as to merit the imposition of yet another bureaucratic, time consuming, and therefore expensive committee intervention?

Audit cannot be value free. The audit process is set to predetermined standards for any given healthcare activity. Best practice is bound to set priorities, and conflicts will arise between benefit to individual patients and demands of management, or perceptions of what is best for the community. Staff shortages, finally officially recognised, have forced the health service to make compromises, which in turn influence the determination of standard setting. These compromises clearly involve value judgments. Care of the mentally ill, the elderly, and the dying currently provide examples where scarce human resources limit best practice. Even in an ideal world, the process of standard setting has to keep up with changes in medical practice as well as keeping abreast of cultural changes.

Ethics committees were brought into the evaluation of research proposals largely because, when unacceptable abuses came to light worldwide, it became necessary for limits to be set on the conduct of research. Clinical audit has tended to be more parochial and less publicly transparent, and if troublesome information has come to light, the public has been less aware of it. Openness is limited by the need to retain confidentiality of those participating in the clinical audit process so as to encourage staff to record the truth fearlessly. Here independent ethics committees - in the United Kingdom every health trust has access to one-can intervene when required to protect the vulnerable. Conflicts may follow from this and the process leading to publication of National Health Service performance league tables.

Ethics committees should be available to evaluate clinical audit, but their involvement should follow strict guidelines of confidentiality, and for reasons already stated hearings probably ought to be by special request in the event of conflicts of interest rather than routine. 